\title{
Trayvon Martin Social Media Messaging: An Analysis of Framing and Media Types in Online Messages by Civil Rights Organizations
}

\author{
RIVA R. BROWN, PH.D. \\ (School of Communication, College of Fine Arts and Communication/University of Central Arkansas, \\ United States of America)
}

\begin{abstract}
This content analysis explores framing and media types used by the NAACP, National Urban League, National Action Network, and ColorOfChange.org in social media during the Trayvon Martin case. After George Zimmerman fatally shot Martin and was not charged with murder, these organizations drafted petitions and staged rallies. Likelihood ratio results show some significant differences in frames. Overall, the results suggest that the organizations could have done more to use multimedia and encourage activism.
\end{abstract}

Keywords - civil rights, social media, activism, content analysis, Trayvon Martin

\section{INTRODUCTION}

The advent of social media has created more avenues for advocacy and activist groups, such as civil rights organizations, to disseminate messages that engage their allies online in encouraging them to effect social and political change. These messages can be framed in ways that bring attention to important issues that could have a detrimental impact on the supporters of those organizations. These messages also can outline specific actions to undertake that ensure that the issues are addressed tactfully, thoughtfully, and thoroughly. Facebook and Twitter allow these organizations to communicate their messages directly to their publics across platforms in an uncontrolled environment. This study applies quantitative content analysis to social media using framing theory to examine issues that occurred during the fight for justice after Trayvon Martin's death. The organizations involved in this study are the National Association for the Advancement of Colored People (NAACP), National Urban League (NUL), National Action Network (NAN), and ColorOfChange.org (COC).

When George Zimmerman, a Hispanic and White male, fatally shot Trayvon Martin, a 17-year-old Black male, in February 2012 in Florida, the killing became the number one news story in the nation the following month ("Trayvon Martin killing," 2012). Additionally, thousands of people signed online petitions and participated in marches and rallies throughout the country to help ensure that Zimmerman faced charges (Alcindor, 2012). Their actions shed light on issues such as racial profiling and the stand-your-ground law, which allows individuals to use deadly force when they fear death or immense bodily harm (Alcindor, 2012; Editorial Desk, 2012).

There are at least three reasons why this content analysis of social media was significant and could contribute to the body of knowledge in mass communications. Firstly, most of the scholarly research about the NAACP and NUL, and their activism and communications strategies and techniques, has been from a historical perspective, whereas no academic studies have examined NAN and COC, as they are relatively new civil rights organizations. Secondly, the NAACP, NUL, NAN, and COC primarily target issues and causes of importance to Blacks, and research shows that Blacks use Twitter at higher rates than other ethnic groups (Duggan \& Brenner, 2013; Smith \& Brenner, 2012). Thirdly, this study examines how the four organizations -- three founded before the Internet was commercialized, the other founded solely to use the Internet -- use the same tools to bring about social and political change.

\section{ORGANIZATION BACKGROUND}

The NAACP, founded in 1909 by a multi-racial and multi-religious group, is the nation's oldest and largest grassroots-based civil rights organization (National Association for the Advancement of Colored People [NAACP], 2009-2013). The National Urban League (NUL), founded in 1910, grew out of a grassroots movement associated with the Black migration from the South to the North (National Urban League, 2013). The National Action Network (NAN), founded in 1991 by television and radio talk show host Reverend Al Sharpton, "works within the spirit and tradition of Dr. Martin Luther King, Jr." (National Action Network, 2011, n.p.). 
ColorOfChange.org (COC) was founded in 2005 after Hurricane Katrina to strengthen the political voice of Blacks. It uses the Internet to empower its members - "to make government more responsive to the concerns of Black Americans and to bring about positive political and social change for everyone" (ColorOfChange.org, 2005-2013, n.p.).

\section{CASE BACKGROUND}

Some key events took place in the Trayvon Martin case between February 26, 2012, and April 11, 2012. On a rainy evening on February 26 in Sanford, Florida, Trayvon Martin was walking from a convenience store to the home of his father's fiancée ("Timeline of events," 2012). Martin got into an altercation with George Zimmerman, a neighborhood watch volunteer ("Trayvon Martin shooting," 2012). Martin was wearing a hoodie and carrying a bag of Skittles, a can of Arizona Iced Tea, and some change. Zimmerman told police he shot and killed Martin in self-defense; therefore, police did not file charges against Zimmerman and he was released ("Timeline of events,"2012; "Trayvon Martin shooting," 2012). On March 8, 2012, Martin's parents called a press conference and asked citizens to sign an online petition calling for Zimmerman's prosecution. The case was turned over to prosecutors. On March 19, 2012, the FBI and the U.S. Department of Justice announced that they planned to investigate the killing, and the Florida State Attorney announced a grand jury investigation.

On March 21, 2012, the same day hundreds of people attended a Million Hoodie March in New York City, the Sanford City Council voted no confidence in Police Chief Bill Lee; the next day he "temporarily" stepped down (Delinski, 2012d). March 23, 2012, includes two significant events in the Trayvon Martin case. First, Geraldo Rivera of Fox News suggested that the "hoodie is as much responsible for Trayvon Martin's death as George Zimmerman was" ("Geraldo Rivera," 2012, n.p.); he apologized a week later. Second, thousands of people attended a Million Hoodie March in Philadelphia, Pennsylvania. By April 3, 2012, 2.2 million people had signed an online petition demanding Zimmerman's prosecution ("The Trayvon Martin case," 2012). On April 10, 2012, Zimmerman's attorneys announced that they would no longer represent him because he stopped communicating with them. The next day, Zimmerman turned himself into police after Florida Special Prosecutor Angela Corey announced that she would charge him with second-degree murder ("The Trayvon Martin case," 2012).

Between February 26, 2012, the day Trayvon Martin was fatally shot, and April 11, 2012, the day George Zimmerman was arrested and charged with Martin's murder, thousands of people across the country signed electronic petitions and letters, and participated in rallies and marches, to demand justice. Martin's parents brought the killing to the national spotlight by calling a press conference and encouraging concerned citizens to sign a Change.org petition demanding that prosecutors charge Zimmerman with murder. Shortly thereafter, representatives from the NAACP, NUL, NAN, and COC became actively involved in organizing and participating in some of these protests. In addition to seeking justice, some of the organizations also used the case to call attention to racial profiling and the controversial Castle doctrine, or stand-your-ground law, which they believe played a role in Martin's death. In Florida, the statute allows people to use deadly force when there is a "presumption of fear of death or great bodily harm" (2011 Florida Statutes: Chapter 776, 2011).

\section{LITERATURE REVIEW}

Individuals and organizations involved in advocacy and activism have been relying on the Internet in general, and social media in particular, to get their supporters more engaged in bringing about social and political change. Before the Internet, organizations and individuals historically used publications, radio, television, and film to mobilize their supporters (Lim \& Kann, 2008). Social media sites such as Twitter and Facebook are a part of the strategies used to get individuals and groups involved in online and offline collective action (Harlow, 2012). Ladhani (2011) argued that social media are powerful tools activists can use to share information, advocate free speech, and organize online.

Twitter is one social media site that has been credited for its role in encouraging offline activism efforts across the globe in countries such as Egypt, Tunisia, Moldova, and Iran. For example, in 2009, actions in Moldova that included protests against the country's Communist government were dubbed the "Twitter Revolution" (Gladwell, 2010, p. 42). However, some critics disputed whether Twitter or any other social media site truly impacts social and political change. Some critics said online activism is for the "faint of heart and referred to it as "slacktivism" and "clicktivism" (Gladwell, 2010; Morozov, 2009; White, 2010). For instance, Gladwell (2010) noted that the NAACP organized the first sit-ins in the late 1950s that laid the groundwork for future protests. In 1960, after four Black North Carolina college students were denied service at a Woolworth lunch counter, a sit-in grew to 27 students the next day and eventually 70,000 across the South (Gladwell, 
Trayvon Martin Social Media Messaging: An Analysis of Framing and Media Types in Online

2010). "These events in the early sixties became a civil-rights war that engulfed the South for the rest of the decade-, and it happened without e-mail, texting, Facebook, or Twitter" (Gladwell, 2010, p. 42). In reference to protests that occurred in 2009 during the Iranian presidential election, which also were dubbed "the Twitter Revolution," Morozov (2009) used the term "slacktivism" to describe what he called "feel-good but useless Internet activism" (p. 13). Similarly, White (2010) used the term "clicktivism" to refer to Internet organizing such as distributing online petitions to spark social change (para. 2). Despite the negative aspects of online activism that Gladwell (2010), Morozov (2009), and White (2010) pointed out, some scholars have found positive aspects of this form of collective action. Christensen (2011) found that even skeptics found at least a weak link between online efforts and offline political participation.

As it relates to mobilizing citizens for political and social change, collective action is a broad concept that can include a group or an individual whose actions are intended to be a part of a collective outcome (Brunsting \& Postmes, 2002). Collective action is undertaken for a purpose "such as the advancement of a particular ideology or idea, or the political struggle with another group" (Brunsting \& Postmes, 2002, pp. 290291). These actions can be considered persuasive or confrontational. Persuasive collective action includes letter writing, lobbying, and petitioning, while confrontational collective actions include demonstrations, blockades, or sabotage (Brunsting \& Postmes, 2002). These actions can be offline and online (Sayed, 2011).

\section{Frames, Tone, and Media Types}

Some scholars have used framing theory to explore how civil rights and other organizations frame their messages to encourage online and offline collective action. Scholars have defined frames in various ways. Entman (1993) asserted that to frame is "to select some aspects of a perceived reality and make them more salient in a communicating text, in such a way as to promote a particular problem definition, causal interpretation, moral evaluation, and/or treatment recommendation for the item described" (p. 52). Entman (1993) also asserted that frames define problems, diagnose causes, make moral judgments, and suggest remedies.

As it relates to collective action frames, Benford and Snow (2000) defined collective action frames and divided them into three categories relating to social movement organizations: diagnostic, prognostic, and motivational. Hallahan (1999) defined the three categories, noting that a diagnostic frame identifies issues that need to be addressed, a prognostic frame proposes a solution to what needs to be done, and a motivational frame works as a call to action to address the issue. Karagiannis (2009) noted that prognostic frames often include injustice frames, while diagnostic frames provide a utopian vision rather than a concrete plan, and motivational frames encourage participation and produce incentives for action. Collective action frames were applied to activism in a study about Hizballah, a group of Shia Muslims formed in 1982 to oppose Israeli invasion and occupation of Lebanon (Karagiannis, 2009). First, Hizballah used the diagnostic frame to interpret "Lebanon's misfortunes as the result of Israeli occupation and the sectarian political system" (Karagiannis, 2009, p. 370). Next, Hizballah used a prognostic frame by proposing the construction of a new Islamic Republic. Finally, Hizballah used motivational frames as emotional rhetoric by invoking Shia narratives and religious symbolism to garner support (Karagiannis, 2009). Collective action frames -- diagnostic, prognostic, and motivational -also were used to analyze audience messages in a study about an online Guatemalan justice movement on Facebook that moved offline (Harlow, 2012).

Muralidharan, Rasmussen, Patterson, and Shin (2011) used the five news frames -- conflict, human interest, economic consequences, morality, and responsibility -- to analyze more than 4,000 Facebook posts and more than 6,600 Twitter tweets related to the 2010 earthquake in Haiti. First, conflict news frames focus on problems between institutions, groups, and individuals, such as during elections (Semetko \& Valkenberg, 2000). Second, human-interest frames apply a human face or emotion to a problem, issue, or event to keep the audience interested. Third, economic consequences frames focus on the how countries, regions, institutions, groups, and individuals will be affected economically. Fourth, morality frames place matters "in the context of religious tenets or moral prescriptions" (Semetko \& Valkenberg, 2000, p. 96). Fifth, responsibility frames attribute responsibility for a cause or solution to an individual, government, or group.

In discussing positive and negative framing, Maheswaran and Meyers-Levy (1990) found that when a subject is highly involved in an issue, messages were more persuasive, subjects viewed them more favorably, and they were more willing to comply with the intentions when they were framed in a negative manner. Conversely, when a subject had low involvement in an issue, he or she had a more favorable opinion of an issue when it was framed positively. Whereas Maheswaran and Meyers-Levy (1990) explored only positive and 
negative framing, other scholars, such as Muralidharan et al., (2011), studied positive, negative, and neutral tones in a content analysis of Facebook and Twitter posts in the aftermath of the earthquake in Haiti.

Media types such as photos, videos, graphics, hashtags, and hyperlinks, which all were used in this study, are devices that can be used to help organizations frame their messages to facilitate online and offline collective action. These messages can be disseminated through Facebook posts and Twitter tweets, which can include hyperlinks to miscellaneous public relations material. In a study analyzing framing devices on environmental and activist organization websites, Zoch, Collins, Sisco, and Supa (2008) identified visual images as one of six, and the least used, framing devices. Zoch et al. (2008) defined visual images as photographs that have not been substantially modified, as well as videos, drawing/animation, and animated text. For instance, videos must include moving real images, while drawing/animation must include the use of computer graphics (Zoch et al., 2008).

Kwok and Yu (2013) also found a low use of visual images such as photos and videos in their analysis of Facebook posts in their study about restaurant business-to-consumer communications. Notwithstanding, the authors found that Facebook posts with photos and short statuses received more likes and comments than other posts (Kwok \& Yu, 2013). Bruni et al. (2012) seemed to support this finding in suggesting that organizations can get their messages more widely distributed across the Twittersphere if they incorporate photos and videos.

Although some research has suggested that some organizations were not using visual images effectively, other research has suggested that they may be using at least one social media mechanism to their benefit. As it relates to hashtags, Bruns and Stieglitz (2013) noted that they help Twitter users and other website visitors without Twitter accounts to "follow real-time feeds of all message containing the hashtag" (p. 2). The authors also noted that hashtags "aid Twitter research by making communicative exchanges comparatively easy to track" (Bruns \& Stieglitz, 2013, p. 2). Nonprofit organizations, including those that advocate civil rights, are among the entities using hashtags in their tweets. Second, in their study analyzing how organizations use Twitter to engage stakeholders in 140 characters or less, Lovejoy, Waters, and Saxton (2012) found that $30 \%$ of 4,655 tweets used by 73 of the nation's largest nonprofit organizations used one or more hashtags. Regarding using Twitter hashtags for protests and other collective action, Segerberg and Bennett (2011) noted that they are "just one of many digital media mechanisms operating to bring publics together to act in concerted or less organized ways" (p. 212).

Another one of those mechanisms that can benefit groups such as civil rights organizations is the hyperlink. Pilny and Shumate (2011) implied that hyperlinks could publicly influence social change offline. The authors conducted research on hyperlinks used on 181 nongovernmental organization (NGO) websites; their findings suggested that hyperlinks were an extension of offline collective action (Pilny \& Shumate, 2011). In a quantitative content analysis study that included hyperlinks, Harlow (2012) analyzed the frequency of various types of hyperlinks used in Facebook comments. Harlow (2012) explored whether those hyperlinks connected to news sites with mainstream or non-mainstream news articles; social media sites such as Facebook and Twitter; or petition, blogs, and other sites (Harlow, 2012). Results showed that 50\% of the hyperlinks connected to news articles and $26 \%$ went to social media sites (Harlow, 2012). Additionally, in a previously noted study related to Facebook and hyperlinks, Kwok and Yu (2013) found that out of nearly 1,000 Facebook messages, more than $31 \%$ included hyperlinks; however, another study related to Twitter found more than double that amount.Lovejoy et al. (2012) found that $68 \%(\mathrm{n}=3,170)$ tweets contained hyperlinks. In another related study, Waters, Burnett, Lamm, and Lucas (2009) analyzed the content of Facebook profiles of 275 legally incorporated non-profit organizations and found that most did not use hyperlinks to provide campaign summaries or post press releases to publicize their causes.

\section{METHODOLOGY}

Based on the literature review, the following hypotheses and research questions were developed.

H1: There will be a significant difference in the type of collective action frame used by the NAACP, NUL, NAN, and COC in their Twitter tweets compared with their Facebook posts.

H2: There will be a significant difference in the type of news frame used by the NAACP, NUL, NAN, and COC in their Twitter tweets compared with their Facebook posts.

H3: There will be a significant difference in the type of tone used by the NAACP, NUL, NAN, and COC in their Twitter tweets compared with their Facebook posts.

RQ1: Is there a significant difference in how often the NAACP, NUL, NAN, and COC refer to offline or online collective action in their Twitter tweets compared with their Facebook posts? 
RQ2: What are the primary media types the NAACP, NUL, NAN, and COC use in their Twitter tweets and Facebook posts about the case?

RQ3: To which websites do the hyperlinks in the Twitter tweets and Facebook posts of each organization primarily connect?

To test the hypotheses and answer the research questions, the researcher conducted quantitative content analysis on the Facebook posts and Twitter tweets of the NAACP, NUL, NAN, and COC. The individual Facebook posts and Twitter tweets served as units of analysis in this study. The time period was February 26, 2012, the day of the fatal shooting, through April 11, 2012, the day Zimmerman was arrested for Martin's murder. The Facebook posts and Twitter tweets came directly from the certified accounts of each organization bearing the organizations' logos and linking to their official websites. Additionally, the samples include tweets from the organizations' leaders, staff members, and related websites, if those tweets appeared on the Twitter feeds of the organizations' certified accounts.

The researcher used a micro-archiving approach by going through the Facebook and Twitter pages of each organization. The researcher collected 853 Twitter tweets and Facebook posts between the four organizations, and coders analyzed 259 of them. The organizations posted 706 Twitter tweets during the sampling frame. Coders analyzed 194 tweets after redundant, unrelated, and miscellaneous ones were deleted. The organizations also made 147 Facebook posts. The coders examined 65 posts after deleting ones that did not pertain to the case. The Twitter tweets and Facebook posts included at least one of the following key words: Trayvon Martin, George Zimmerman, Sanford, Florida, stand your ground, shoot first, and kill at will laws. The tweets also included any of the following Twitter hashtags: \#TrayvonMartin, \#Trayvon, \#Justice4Trayvon, \#JusticeforTrayvon, \#MillionHoodies, \#ALEC, \#NRA, \#stopALECNRA4Trayvon, \#standyourgroundlaws and \#tweetupfortrayvon.

\section{Reliability and Coding Categories}

The researcher and two other coders were involved in this study. The first coder was an undergraduate social science major who was paid $\$ 60$. The second coder holds a Ph.D. in mass communication; this coder did not receive compensation. The researcher and the first coder participated in at least 10 hours of training over a two-day period. They also conducted a pre-test, identified and corrected areas of disagreement, and revised some variable operational definitions. Intercoder reliability was conducted using Cohen's Kappa for an overall rating of $86.22 \%$, exceeding the acceptable level of $80 \%$. The first coder analyzed $75 \%$ of the sample, while the researcher analyzed the remaining $25 \%$.

To test H1, collective action frames were coded as diagnostic, prognostic, and motivational. Collective action frames refer to tasks that tell what must be done and what must be achieved in mobilizing people to act.For H2, news frames were coded as conflict, human interest, economic consequences, morality, and responsibility. News frames refer to tools the media and individuals rely on to convey, interpret and evaluate information.

$\mathrm{H} 3$ related to tone was coded as positive, negative, or neutral. Positive tones showed good feelings such as pride, love, and enthusiasm and included pro-Trayvon Martin and pro-voting posts and tweets. Negative tone showed bad feelings such as hatred, anger, or disgust and included anti-George Zimmerman, anti-racial profiling, and anti-ALEC sentiments. To address RQ1, the Facebook posts and Twitter tweets were coded as offline, online, both, or neither. Online collection action refers to an activity that can be done from a computer or mobile device.

Offline collection action refers to an activity that often requires being physically present.

In RQ2, the samples were coded yes or no based on whether they included a photo, video, graphic, hyperlink, hashtag, or all of them. In RQ3, each hyperlink included in the Facebook post or Twitter tweet was clicked on and coded either yes or no based on whether it connected to the organization's site, or a news, social media, or another organization's site.

\section{RESULTS}

For H1, a likelihood ratio test was calculated as an alternative, revealing a significant difference $\left(\chi^{2}(6)\right.$ $=29.09, \mathrm{p}<.001$, two-tailed) and thereby supporting H1. Overall, the organizations were most likely to use the diagnostic collective action frame $(47.9 \%, \mathrm{n}=124)$ followed by motivational $(39.8 \%, \mathrm{n}=103)$ and prognostic $(32 \%, \mathrm{n}=124)$ frames. NUL, NAN, and COC all were most likely to use the diagnostic frame $(50.9 \%, \mathrm{n}=28$; $61.5 \%, \mathrm{n}=16,45.9 \%, \mathrm{n}=51)$, while the NAACP was most likely to use the motivational frame $(52.2 \%, \mathrm{n}=35)$. 
Trayvon Martin Social Media Messaging: An Analysis of Framing and Media Types in Online

The organizations used diagnostic frames when they referred to specific issues that needed to be addressed, such as racial profiling, the so-called stand-your-ground laws and groups that back such legislation, such as the American Legislative Exchange Council (ALEC) and the National Rifle Association (NRA). The organizations relied on motivational frames when they encouraged their Twitter followers to stand for justice, share their stories online, attend rallies and marches, and support Martin's family. The organizations used prognostic frames when they referred to ways to end violence and sever ties with groups that support the Castle Doctrine, which they described as the stand-your-ground, kill-at-will or shoot-first law. A likelihood ratio test also revealed a significant difference between the collective action frame and Twitter tweets and Facebook posts $\left(\chi^{2}\right.$ $(2)=20.64, \mathrm{p}<.001$, two-tailed). Twitter tweets most likely used the diagnostic collective action frame $(53.1 \%$, $\mathrm{n}=103)$, while Facebook posts primarily used the motivational frame $(63.1 \%, \mathrm{n}=41)$.

For $\mathrm{H} 2$, the alternative likelihood ratio test revealed a significant difference between the news frame and the organization $\left(\chi^{2}(6)=26.53, \mathrm{p}<.001\right.$, two-tailed); therefore, H2was supported. Collectively, the organizations most likely used conflict $(44.8 \%, \mathrm{n}=116)$ followed by the human interest $(29.7 \%, \mathrm{n}=77)$ and responsibility $(25.5 \%, \mathrm{n}=66)$ news frames. None of the organizations used the morality or economic consequences news frames in their Twitter tweets and Facebook posts. Individually, NUL and COC primarily used the conflict news frame $(50.9 \%, \mathrm{n}=28 ; 52.3 \%, \mathrm{n}=58)$; however, the NAACP and NAN primarily used the human-interest frame $(43.3 \%, \mathrm{n}=29 ; 53.8 \%, \mathrm{n}=14)$. An example of a conflict frame the NUL used in a tweet read, "Protest 'Kill at Will' Laws that Are Killing Innocent People and Protecting Vigilantes." The alternative likelihood ratio test also reflected a significant difference $\left(\chi^{2}(2)=33.38, p<.001\right.$, two-tailed) between the news frame Facebook posts and Twitter tweets. Twitter tweets used the conflict news frame $(54.6 \%, n=106)$, while Facebook posts primarily used the human-interest news frame (44.7\%, n=31). An example of a NAN Facebook post that used a human-interest frame mentioned that Reverend Al Sharpton would give keynote remarks at a national rally for justice along with special guest host Michael Baisden, a nationally syndicated radio show at the time. Additionally, the post mentioned that Martin's parents, attorney Benjamin Crump, and lawyers for Martin's family, would attend.

For H3, the alternative likelihood ratio test revealed no significant difference between the tone and the organization $\left(\chi^{2}(6)=13.09, \mathrm{p}=.04\right.$, two-tailed); therefore, H3 was not supported. Collectively, the organizations most likely used a neutral tone $(62.9 \%, \mathrm{n}=163)$ followed by a positive then a negative $(22.4 \%, \mathrm{n}=58,14.7 \%$, $\mathrm{n}=38$ ). When analyzed individually, the organizations used a neutral followed by a positive and negative tone. The COC posted an example of this tweet with a negative tone: "If racial profiling and tolerance and ignorance is the gunpowder then alec and its series of laws is the match! @ rashadrobinson." Both Twitter tweets and Facebook posts most likely used a neutral tone $(63.9 \%, \mathrm{n}=124 ; 60.0 \%, \mathrm{n}=39)$.

For RQ1, the alternative likelihood ratio test revealed a significant difference in action type and the organization $\left(\chi^{2}(9)=52.69, \mathrm{p}<.001\right.$, two-tailed); therefore, RQ1was supported. Overall, the organizations advocated online action $(55.6 \%, \mathrm{n}=144)$ followed by no action, offline action or both $(22.8 \%, \mathrm{n}=59 ; 11.2 \%$, $\mathrm{n}=29,10.4 \%, \mathrm{n}=27)$. Individually, the NAACP, NUL, and COC were most likely to advocate online action $(64.2 \%, \mathrm{n}=43 ; 54.5 \%, \mathrm{n}=30 ; 60.4 \%, \mathrm{n}=67)$, while NAN was most likely to advocate offline action $(30.8 \%, \mathrm{n}=8)$. Online action referred to activities such as signing online petitions, submitting photos and stories online, and tweeting using a certain hashtag. Offline action referred to activities such as attending rallies, marches, and public meetings. A likelihood ratio test also revealed a significant difference in the action type and Twitter tweets and Facebook posts $\left(\chi^{2}(3)=46.37, \mathrm{p}<.001\right.$, two-tailed). Twitter tweets most likely advocated online action $(49.4 \%, \mathrm{n}=66)$, while Facebook posts most likely advocated offline action $(30.8 \%, \mathrm{n}=20)$.

For RQ2, results show that collectively, the four organizations primarily used videos $(27.4 \%, n=71)$ followed by photos $(18.9 \%, \mathrm{n}=49)$ and graphics $(12.0 \%, \mathrm{n}=31)$. Individually, the NAACP and NAN were more likely to use photos $(25.4 \%, \mathrm{n}=17 ; 15.4 \%, \mathrm{n}=4)$, while NUL and COC were more likely to use videos $(43.6 \%$, $\mathrm{n}=24 ; 28.8 \%, \mathrm{n}=32)$. As it relates to hashtags, the NAACP and COC were more likely to use them $(59.7 \%$, $\mathrm{n}=40 ; 57.7 \%, \mathrm{n}=64)$. Concerning photos, the NAACP tweeted links to Facebook photo albums to illustrate its offline activism efforts. Concerning videos, the NUL tweeted links to videos featuring Marc Morial's television interviews about the Trayvon Martin case on CNN's "Starting Point with Soledad O'Brien" and MSNBC's "Andrea Mitchell Reports." Next, the NAACP posted a video featuring a video of President Benjamin Jealous appearing on NBC's "Meet the Press" to discuss the case. Finally, COC posted and tweeted several links to a video hip-hop activist Jasiri X made about Trayvon Martin.

The combined Twitter tweets and Facebook posts were more likely to use video $(27.4 \%, \mathrm{n}=71)$ while graphics were the least likely to be used $(12.0 \%, n=31)$. With respect to Twitter tweets, videos were the most 
used media type $(32.0 \%, \mathrm{n}=62)$; however, with regard to Facebook posts, photos were used most often $(44.6 \%$, $\mathrm{n}=29)$. As it relates to hashtags, more than half of all Twitter tweets contained them $(61.9 \%, \mathrm{n}=120)$. The NAACP also made at least three posts showing NAACP leaders, employees, and members wearing hoodies in solidarity with the movement for justice in the case. For example, a post read, "Do they look suspicious?" and featured a photo of a serious-looking President Benjamin Jealous holding a can of Arizona Iced Tea, and Board of Directors Chairman Roslyn Brock holding a bag of Skittles, while standing in front of a waist-high replica of the NAACP' s official logo. With regard to graphics, COC posted links to different versions of fliers and graphics for supporters to "download, share and print" for their windows or for use when attending local events. Additionally, NUL posted a graphic on Facebook that changed the letters A-L-E-C, an acronym for the American Legislative Exchange Council, to stand for Advancing Legislation that Exonerates Criminals.

In RQ3, all of the organizations were most likely to include hyperlinks to their official websites $(33.2 \%, \mathrm{n}=86)$ followed by news sites $(11.6 \%, \mathrm{n}=30)$, Facebook and Twitter sites $(10.4 \%, \mathrm{n}=27)$, another organization's website $(5.4 \%, \mathrm{n}=14)$, and a petition $(2.7 \%, \mathrm{n}=7)$. First, the COC was most likely to provide hyperlinks to its website $(56.8 \%, \mathrm{n}=63)$, while the NAACP and NAN were least likely to link to petitions $(0.0 \%$, $\mathrm{n}=0$ ). The NUL and NAN provided an equal number of hyperlinks to their websites and social media sites $(18.2 \%, \mathrm{n}=10 ; 15.4 \%, \mathrm{n}=4)$.

The COC often linked back to a special web page it created specifically for the Trayvon Martin case. In terms of links to other organizations' websites, the COC tweeted links to a website that encouraged their supporters to write a letter to the editors of their local newspapers to help tell Martin's story, while NUL tweeted links to the Center for Media and Democracy, which worked to expose the American Legislative Exchange Council's role in stand-your-ground legislation. In this case, the combined Twitter tweets and Facebook posts most likely included hyperlinks to the organization's official website $(33.2 \%, \mathrm{n}=86)$ followed by news sites $(11.6 \%, \mathrm{n}=30)$, social media sites $(10.4 \%, \mathrm{n}=27)$, other organizations" websites $(5.4 \%, \mathrm{n}=14)$, and online petitions $(2.7 \%, \mathrm{n}=7)$. This ranking also was the case for Twitter tweets.

\section{DISCUSSION AND CONCLUSION}

H1 examined the difference in the collective action frame by organization and social media type. Among the organizations, the NAACP was more likely to use the motivational frame, which supported Harlow (2012). This suggested that the organization relied on methods it has used throughout its history: rallying support through meetings and speeches (O'Brien, 2011). The other organizations, however, were more likely to use the diagnostic frame. The primary use of this frame suggested that NUL and COC focused the majority of their Twitter tweets and Facebook posts on increasing awareness about issues such as the impact of racial profiling, particularly on young Black males, and the overarching agenda of the groups behind writing and promoting legislation for the so-called stand-your-ground laws, of which many supporters may not have been aware. The COC and NUL published several pieces about the roles ALEC and the NRA played in getting major corporations such as McDonald's to stop funding ALEC. The COC referred to this as the "cause behind the cause." Using the diagnostic approach suggested that the organizations chose to use the case as a catalyst to focus on the impact of the big-picture issues with a potential long-term impact. This approach perhaps was more beneficial than the motivational approach that focused on honoring the memory of one person by attending marches and rallies and posting hoodie photos; these efforts appeared to have a short-term impact. Furthermore, because the mainstream news media already had focused a great deal of attention on the aforementioned activism efforts, relying primarily on the diagnostic frame seemed more appropriate because of its ability to educate and inform.

$\mathrm{H} 2$ addressed the news frames the organizations used. Of the five types of news frames, nearly half of the Facebook posts and Twitter tweets incorporated a conflict news frame. The organizations' primary use of this frame, particularly by the COC and NUL, contradicted findings by Muralidharan et al. (2011), who found that attribution of responsibility was the dominant news frame on Twitter, while morality was dominant on Facebook. The nature of this case, however, suggested that the conflict frame was appropriate because of the caustic nature of the case and the level of acrimony with individuals and institutions involved. Individuals included the accused murderer, the police chief, and the special prosecutor; institutions included ALEC and NRA, along with their corporate backers and the police department. As it relates to the human-interest frame, NAN and the NAACP primarily used it, in part, to promote the roles of their leaders in their pursuit of justice, perhaps because of Sharpton's name recognition and notoriety. Shifting a human-interest focus to Martin's 
family or other Black families whose loved ones were victims of racial profiling or stand-your-ground laws would have helped to underscore the urgency of the big-picture issues. Given that results show that the Facebook posts primarily had a human-interest frame, perhaps incorporating more photos of the previously mentioned families would have further illustrated the oft-repeated We Are Trayvon mantra.

$\mathrm{H} 3$ explored the tone the organizations used in their Twitter tweets and Facebook posts, as well as the tone regional and national newspapers used in their articles citing the organization's involvement in the case. On the Twitter tweets and Facebook posts, all of the organizations used a neutral tone more than half of the time.

RQ1 examined whether there is a difference in how often the organizations refer to offline or online collective action in their Twitter tweets and Facebook posts, if at all. With the exception of NAN, all of the organizations predominantly referred to online collective action more than half the time. The finding related to NAN suggested that the Twitter tweets and Facebook posts reflected Sharpton's highly publicized past and present involvement in offline activism such as protests, rallies, and marches. The NAACP also is perhaps best known for its offline activism efforts, so the finding that nearly two-thirds of its social media posts refer to online activism efforts suggested that the organization may be revamping its image to appeal to a younger generation of potential civil rights activists who are actively engaged in online activities. This point also can be applied to NUL. Furthermore, although results show the NAACP had the highest percentage of references to online activism, the COC had the largest number, which reflects back to the reason why the organization was founded: to encourage Blacks to engage in online activism. For example, the COC created an online letter addressed to the U.S. Justice Department for its supporters to sign. However, the findings that about a third of the COC' s Twitter tweets and Facebook posts did not advocate any action suggested that the organization could consider being more strategic in crafting social media messages that inform its supporters while also encouraging them to become actively involved.

RQ2 inquired about the primary media types the organizations use in their Facebook posts and Twitter tweets. With regard to hashtags, more than half of the Twitter tweets about the case used hashtags, while none of the Facebook posts did so. Because hashtags in the social networking environment originated for use on Twitter, it stands to reason that no Facebook posts would include them. The findings related to the Twitter hashtags far exceeded those in Lovejoy et al. (2012); however, it must be noted that those researchers studied the tweets of 73 organizations, whereas this study used only four. Although a large number of the tweets contained hashtags, using a select few of them in more, if not all, of the tweets could have enhanced their brand and served as a publicity tool to increase awareness about the organization in general and its activism efforts in particular. For example, using more hashtags could have allowed Twitter users who may not have been familiar with these organizations and also were searching for information about the case to perhaps learn more about them. With regard to visual images, the organizations were more likely to use videos over photos and graphics, respectively. Collectively, less than half of all the Twitter tweets and Facebook posts about the case contained visual images. These findings supported Zoch et al. (2008) and Kwok and Yu (2013); however, it must be noted that more than half of these social media elements for the COC and NUL contained photos, videos, and graphics.

Incorporating more videos than photos was another method the organizations could have used to distribute their messages beyond the written word and make them more salient. It is worth pointing out, however, that the organizations did not create some of the videos; instead, they included links from news media that interviewed their leaders. It also is important to note that some Twitter tweets and Facebook posts contained multiple photos in albums; therefore, the total amount of photos used would significantly outnumber the videos. Nonetheless, these findings suggested three key points. First, given the number of marches, rallies, and public meetings in which the four organizations were involved, the organizations could have dedicated more manpower toward shooting photos and videos of each event to properly document their activism efforts and tell their stories from their perspective. Doing so could have given the organizations more control over their image, enhance their visibility, increase message saliency, and lessen reliance on the news media to disseminate their messages. Second, the organizations perhaps could have included more photos, especially in Facebook posts, because the proliferation of smart phones and other technology makes it easier to quickly and inexpensively shoot, edit, and upload professional quality photos more readily than videos. Third, the organizations could have considered doing more to incorporate even more photos and videos into their social media sites, especially with the popularity of smart phones being used to watch short videos on sites such as YouTube and now Instagram, the latter of which is primarily used to view photos that can be posted directly to Facebook and Twitter. More people than ever before are watching videos on their mobile devices via sites such as YouTube, particularly 
people of color (Moore, 2011). Non-Whites, including Blacks and Hispanics, who are the primary target audience for the civil rights organizations in this study, use video-sharing sites more than Whites at a rate of $79 \%$ to $69 \%$ (Moore, 2011). Additionally, Twitter is especially appealing to Blacks, and Instagram is especially appealing to Blacks and Hispanics (Duggan \& Brenner, 2013).

RQ3 inquired about the websites in which the hyperlinks in the Twitter tweets and Facebook posts primarily connect. Overall, more than half of the organizations included hyperlinks in their Twitter tweets and Facebook posts, but individually, COC and NUL were the only organizations to do so. This finding seemed to support Lovejoy et al. (2012). Of those hyperlinks, having the majority of them link back to related information on the organizations' official websites suggested several things: 1) their Twitter followers and Facebook friends could get more in-depth information about the case and more opportunities to engage in online and offline action; 2) they would get more exposure to more aspects of the organizations' social and political agendas beyond the case; and 3) if they were not already members, they might be persuaded to join or contribute financially. Beyond linking back to their websites, the findings that they link back to news sites and other social media sites respectively supported similar findings from Harlow (2012). In summary, this study primarily explored how the NAACP, NUL, NAN, and COC used frames and media types in their social media messages to facilitate collective action. The findings in each case revealed some key differences in the frames, media types, and references to online and offline activism.

Regarding collective action frames, these civil rights organizations chose diagnostic as the dominant frame. Disseminating key messages in the initial phase of the case was a one-time occurrence that perhaps required using a frame that helped to identify issues that needed to be addressed to both educate and inform audiences. Additionally, with the large degree of news media coverage about ways people across the country had gotten involved, the organizations may have thought a motivational frame was unnecessary. The leaders of these civil rights organizations, as well as others involved in writing and distributing messages for similar advocacy and activist groups, can learn from these examples that it may be best to use collective action frames that best fit the case rather than use a one-frame-fits-all approach. Regarding news frames, the organizations opted for more conflict frames in the case. As previously pointed out, the nature of each case likely resulted in the organizations framing their messages differently. Given the high degree of controversy involved in the case that the organizations and their allies actively confronted, using the conflict news frame was not surprising. Some points that can be discerned from these examples are that organizations could select appropriate news frames on a situational basis, and they could make an effort to ensure interconnectivity if multiple frames are used. Regarding media types, specifically photos, videos, and graphics, percentage-wise the organizations used videos the most in the Trayvon Martin case. This perhaps was the case because the organizations garnered considerably more media coverage during the beginning of the case. As a result, they posted hyperlinks to television news stories that featured interviews with the leaders of the organizations. They also posted hyperlinks to videos others created to honor Martin's memory. Overall, the organizations could have done a better job incorporating multimedia elements throughout their Facebook posts and Twitter tweets. Additionally, they could have at least considered adding photos to their press releases and official statements, which only contained words. Regarding references to online or offline activism versus no activism in their Twitter tweets and Facebook posts, most of the organizations advocated online in the case. What can be ascertained from these examples is that all messages, no matter how small, could incorporate a call to action.

The organizations used collective action and news frames, media types, and references to online and offline activism in their messages related to the case. Additionally, they all predominantly used the same neutral tone in their Facebook posts and Twitter tweets. As previously noted, the organizations likely chose this tone to avoid further sensationalizing sensitive issues. It must be pointed out, however, that sometimes using positive or negative tones can help make messages more impactful. For instance, as stated in the literature review, people who are highly involved in an issue are more willing to comply with requests when they are framed negatively (Maheswaran \& Meyers-Levy, 1990). This suggested that messages distributed in the case could have resulted in more online or offline activism if they had a negative tone. Furthermore, as also asserted in the literature review, when people have a low level of involvement in an issue, positive framing may pique their interests (Maheswaran \& Meyers-Levy, 1990). Public relations writers for civil rights organizations and other entities can learn from these instances that taking the middle road by remaining neutral may not be the best method when crafting messages designed to spur collective action.

Finally, as it relates to social media, one last practical suggestion would have been for the organizations to have considered ensuring that all Twitter tweets come from their official Twitter accounts. Similarly, they 
Trayvon Martin Social Media Messaging: An Analysis of Framing and Media Types in Online

could have considered making sure most of their Facebook posts were original statuses. Regarding the number of tweets on official Twitter accounts, case results showed 68\% on the organizations' feeds. The remaining tweets came from the organizations' leaders, staff members, or a site related to the organization. These results suggested that each organization perhaps could strengthen its brand and give their messages more impact by addressing their audiences with only one voice -- the organization's voice -- because organizations generally have more credibility than individuals. Regarding the type of Twitter tweets and Facebook posts the organizations used, results showed they created $86.5 \%$ in this case. The remainders were retweets, modified tweets, shared hyperlinks and shared photos on Facebook. Posting more Facebook statuses they authored could make the organizations appear more authoritative and make their audiences pay more attention to their messages. In summary, strategically incorporating the appropriate frames and tone in their messages on a situational basis, as well as using more multimedia elements in all their messages, could help the organizations generate more mainstream media coverage, encourage more individuals to engage in online and offline activism, and ensure that they fulfill their mission and agenda.

\section{Limitations and Future Research}

This study has limitations that include sample sizes and the number of organizations. A limited number of Twitter tweets and Facebook posts were coded, and samples of some organizations that were not comparable to the sample sizes of other organizations. Finally, this study was limited to only four civil rights organizations and was based on a short time period. Future research could explore audience response, specifically whether they engaged in online or offline activism because of the messages the organizations posted online. Secondly, future research could explore the number of likes and comments on Facebook posts regarding the Trayvon Martin case to determine whether the commenters indicated their intentions to support the organizations by participating in online and offline activism. On a similar note, future research also could explore whether and how often the messages on Twitter got retweeted or favorited, as well as whether the Twitter followers added their comments to the tweet before distributing it to their followers. Thirdly, future research could determine how many of the Facebook friends and Twitter followers of the organizations actually signed petitions, registered to vote or attended marches, meetings, and rallies compared to members of the organizations. Finally, future research could expand on the number of civil rights organizations and compare whether, for example, the frames and media types used at the beginning of the Trayvon Martin case changed. Overall, future research could be used to provide civil rights organizations with a practical approach to help ensure that their messages can influence others to play an active role in effecting political and social change.

\section{REFERENCES}

[1] Trayvon Martin killing is public's top news story. (2012, March 27). Retrieved July 29, 2012, from http://www.people-press.org/2012/03/27/trayvon-martin-killing-publics-top-news-story/

[2] Editorial Desk. (2012, April 17). Embarrassed by Bad Laws. New York Times, 24A.

[3] Duggan, M., \& Brenner, K. (2013, February 14). The Demographics of Social Media Users - 2012. Retrieved from http://pewinternet.org/Reports/2013/Social-media-users/The-State-of-Social-MediaUsers.aspx

[4] Smith, A., \& Brenner, J. (2012, May 31). Twitter Use 2012. Retrieved July 29, 2012, from http://pewinternet.org/Reports/2012/Twitter-Use-2012/Findings.aspx

[5] National Association for the Advancement of Colored People. (2009-2013). http://www.naacp.org/; https://twitter.com/NAACP

[6] National Urban League. (2013). http://nul.iamempowered.com; https://twitter.com/NatUrbanLeague/

[7] National Action Network. (2011). http://nationalactionnetwork.net/; https://twitter.com/nationalaction

[8] ColorOfChange.org. (2005-2013). http://www.colorofchange.org/; https://twitter.com/ColorOfChange

[9] Timeline of events in Trayvon Martin case. (2012, April 23). Retrieved July 29, 2012, from http://articles.cnn.com/2012-04-23/justice/justice_florida-zimmerman-timeline_1_gated-communitygunshot-martin-punches?_s=PM:JUSTICE

[10] Trayvon Martin shooting timeline. (2012, April 9). Retrieved July 29, 2012, from http://www.usatoday.com/news/nation/story/2012-04-09/trayvon-martin-timeline-floridashooting/54129274/1 
Trayvon Martin Social Media Messaging: An Analysis of Framing and Media Types in Online

[11] Delinski, R. (2012a, March 17). Sanford police release 911 calls in Trayvon Martin shooting. The Sanford Herald. Retrieved from http://mysanfordherald.com

[12] Geraldo Rivera: Trayvon Martin's hoodie is as much responsible for his death as George Zimmerman. (2012, March 23). Retrieved July 29, 2012, from http://video.foxnews.com/v/1525652570001/geraldorivera-trayvon-martins-hoodie-is-as-much-responsible-for-his-death-as-george-zimmerman/

[13] The Trayvon Martin case: A timeline (2012, March July 17). Retrieved July 29, 2012, from http://theweek.com/article/index/226211/the-trayvon-martin-case-a-timeline

[14] 2011 Florida Statutes: Chapter 776. Justifiable Use of Force. (2011). Retrieved July 29, 2012, from http://www.flsenate.gov/Laws/Statutes/2011/Chapter0776/All

[15] Lim, M., \& Kann, M. E. (2008). Politics: Deliberation, mobilization and networked practices of agitation. Networked Publics, 77-107. Retrieved July 29, 2012, from http://www.public.asu.edu/ mlim4/files/Lim_Kann_2008.pdf

[16] Harlow, S. (2012). Social media and social movements: Facebook and an online Guatemalan justice movement that moved offline. New Media \& Society, 14(2), 225-243.

[17] Ladhani, N. (2011). The Organizing Impact of Social Networking. Social Policy, Winter, 57.

[18] Gladwell, M. (2010). Small change. New Yorker, 86(30), 42.

[19] Morozov, E. (2009). Iran: Downside to the "Twitter Revolution." Dissent (00123846), 56(4), 10.

[20] White, M. (2010, November 17). Activism after clicktivism: How to energize the political left. Downloaded from http://www.adbusters.org/magazine/93/activism-after-clicktivism.html

[21] Christensen, H. S. (2011, February 7). Political activities on the Internet. Slacktivism or political participation by other means? First Monday, (16)2. Retrieved July 29, 2012, from http://firstmonday.org/htbin/cgiwrap/bin/ojs/index.php/fm/article/viewArticle/3336/2767

[22] Methodology, 16(2), 91-108.

[23] Brunsting, S., \& Postmes, T. (2002). Social movement participation in the digital age: Predicting offline and online collective action. Small Group Research, 33(5), 525-554.

[24] Sayed, N. (2011). Towards the Egyptian Revolution: Activists' perceptions of social media for mobilization. Journal of Arab \& Muslim Media Research, 4(2\&3), 273-298.

[25] Entman, R. E. (1993). Framing: Toward Clarification of a Fractured Paradigm. Journal of Communication, 43(4),51-58.

[26] Benford, R. D., \& Snow, D. A. (2000). Framing processes and social movements: An overview and Assessment. Annual Review of Sociology, 26(1), 611.

[27] Hallahan, K. (1999). Seven models of framing: Implications for public relations. Journal of Public Relations Research, 11(3), 205-242.

[28] Muralidharan, S., Rasmussen, L., Patterson, D., \& Shin, J. (2011). Hope for Haiti: An analysis of Facebook and Twitter during the earthquake relief efforts. PublicRelations Review, 37, 175-177.

[29] Semetko, H. A., \& Valkenburg, P. M. (2000). Framing European politics: A content analysis of press and television news. Journal of Communication, 50(2), 93-109.

[30] Maheswaran, D., \& Meyers-Levy, J. (1990) The Influence of Message Framing and Issue Involvement. Journal of Marketing Research, 27, 361-367.

[31] Zoch, L. M., Collins, E. L., Sisco, H. F., \& Supa, D. H. (2008). Empowering the activist: Using framing devices on activist organizations' web sites. Public Relations Review, 34(4), 351-358.

[32] OrlandoSentinel.com.

[33] Kwok, L., \& Yu, B. (2013). Spreading social media messages on Facebook: An analysis of restaurant business-to-consumer communications. Cornell Hospitality Quarterly, 54(1), 84-94. doi: $10.1177 / 1938965512458360$

[34] Bruns, A., \& Stieglitz, S. (2013). Towards more systematic Twitter analysis: metrics for tweeting activities. International Journal Of Social Research Methodology, 16(2), 91-108.

[35] Lovejoy, K., Waters, R. D., \& Saxton, G. D. (2012). Engaging stakeholders through Twitter: How nonprofit organizations are getting more out of 140 characters or less. Public Relations Review, 38(2), 313-318.

[36] Segerberg, A., \& Bennett, W. (2011). Social Media and the Organization of Collective Action: Using Twitter to Explore the Ecologies of Two Climate Change Protests. Communication Review, 14(3), 197215. 
Trayvon Martin Social Media Messaging: An Analysis of Framing and Media Types in Online

[37] Pilny, A., \& Shumate, M. (2011). Hyperlinks as extensions of offline instrumental collective action. Information, Communication \& Society, 15(2), 260-286.

[38] Waters, R. D., Burnett, E., Lamm, A., \& Lucas, J. (2009). Engaging stakeholders through social networking: How nonprofit organizations are using Facebook. Public Relations Review,35, 102-106. 